\title{
The association between diabetes numeracy and diabetes self-management among Saudi adults with insulin-treated diabetes
}

Hiba Y. Alruhaim, MBBS, SBFM, Turky H. Almigbal, SBFM, CFPDMCDM, Joud S. Almutairi, MBBS, SBFM, Muhammad H. Mujammami, SBIM, SBEM, Turki A. AlMogbel, SBFM, Abdullah A. Alrasheed, SBFM, Abdullah M. Al Zahrani, MBBS, SBFM, Mohammed A. Batais, SBFM, CFPDMCDM.

\begin{abstract}
الأهداف : وصف العلاقة بين مستوى المهارات الحسابية لمرضى السكري والعناية

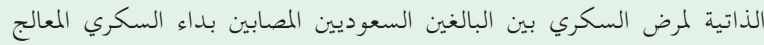

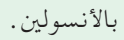

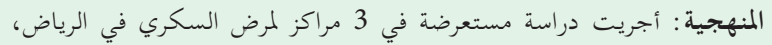

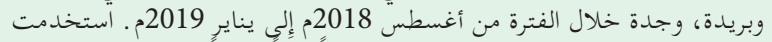

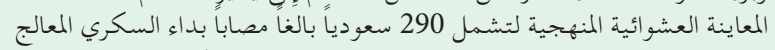

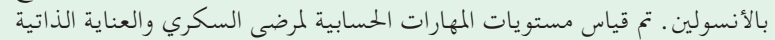

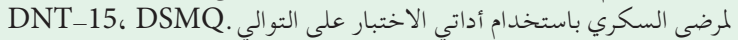

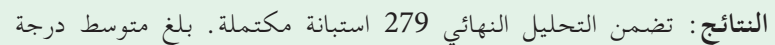

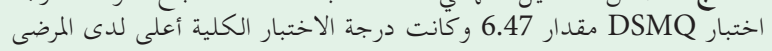
ذوي المستوى التعليمي الأدنى (

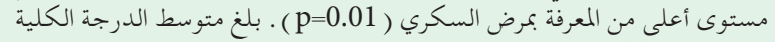

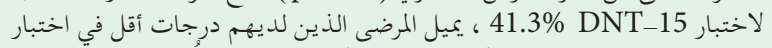

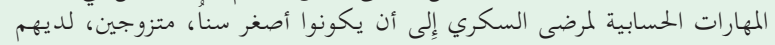

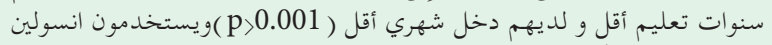

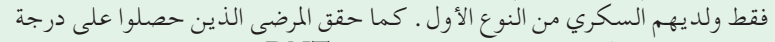

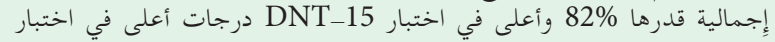
p=0.17 DSMQ

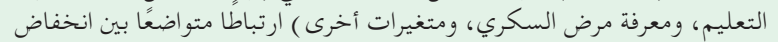

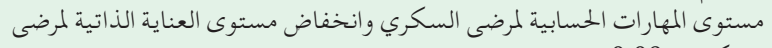
السكري (p=0.08) ( )

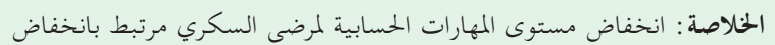
مستوى العناية الذاتية لمرضى السكري المهاري.
\end{abstract}

Objectives: To describe the association between diabetes numeracy and diabetes self-management among Saudi adults with insulin-treated diabetes.

Methods: From August 2018 to January 2019, a crosssectional study was conducted in 3 diabetes centers in Riyadh, Buraydah, and Jeddah, Saudi Arabia. Systematic random sampling was used to include 290 Saudi adults with insulin-treated diabetes. The levels of diabetes numeracy and diabetes self-management were measured by using the Diabetes Numeracy Test tool (DNT-15) and Diabetes Self-Management Questionnaire tool (DSMQ).
Results: The final analysis included 279 completed surveys. The mean total score of DSMQ was 6.47. The total DSMQ score was higher among patients who had a lower level of education $(p=0.02)$, and patients who had a higher level of diabetes knowledge $(p=0.01)$. The mean total score of DNT-15 was $41.3 \%$. Patients who had lower diabetes numeracy scores tended to be younger, married, have fewer years of education, have a lower monthly income $(p<0.001)$, use insulin only, and have type 1 diabetes. Patients who achieved a total score of $82 \%$, and higher in DNT-15 have also achieved the highest score in DSMQ $(p=0.17)$. A linear regression analysis adjusted for level of education, diabetes knowledge, and other variables found a modest association between low diabetes numeracy and low diabetes self-management $(p=0.08)$.

Conclusion: Lower level of diabetes numeracy was associated with lower level of diabetes self-management.

Keywords: diabetes, numeracy, insulin, self management

Saudi Med J 2021; Vol. 42 (5): 517-525

doi: 10.15537/smj.2021.42.5.20200422

From the Department of Family and Community Medicine (Alruhaim, Almigbal, Almutairi, Alrasheed, Batais), from the Endocrinology and Metabolism Unit (Mujammami), College of Medicine, King Saud University; from the Vision College of Medicine, Vision Colleges (Almigbal); from the King Saud University Medical City (Almigbal, Mujammami, Alrasheed, Batais), Riyadh; from the Department of Family Medicine (Al Zahrani), King Saud bin Abdulaziz University for Health Sciences, King Abdulaziz Medical City, Jeddah; and from the Buraydah Diabetes Centre (AlMogbel), King Fahd Specialist Hospital, Buraydah, Kingdom of Saudi Arabia.

Received 3rd March 2021. Accepted 22nd March 2021.

Address correspondence and reprint request to: Dr. Hiba Alrubaim, Department of Family and Community Medicine, College of Medicine, King Saud University, Riyadh, Kingdom of Saudi Arabia. E-mail:hibah.y.r@hotmail.com

ORCID ID: http://orcid.org/0000-0003-0970-0970 
$\mathrm{D}$ iabetes is one of the most common chronic conditions in both developing and developed countries. According to the 2019 report by the International Diabetes Federation, Saudi Arabia has the second highest prevalence of diabetes among Middle Eastern and North African countries. ${ }^{1}$ Poorly controlled diabetes can lead to several complications including cardiovascular disease, retinopathy, nephropathy, and neuropathy, any of which can cause significant morbidity and mortality. Ultimately, diabetes is a massive burden on society; nevertheless, diabetes control among Saudi adults with diabetes remains suboptimal. ${ }^{2-4}$

People with diabetes are expected to participate in managing their disease by performing certain selfmanagement activities which include adherence to a healthy diet and medication regimen, regular exercise, foot care, and blood glucose monitoring. ${ }^{5}$ Diabetes selfmanagement was found to significantly predict glycemic control $^{6-8}$ and positively correlate to a reduction in the number of complications and an improvement in quality of life. ${ }^{9,10}$ Patients with diabetes, especially if receiving insulin, are often required to employ more complex skills such as interpreting blood glucose readings, adjusting medication doses, and calculating carbohydrate intake. ${ }^{11-14}$ Such essential practices require adequate mathematical skills, which are also called numeracy skills.

Numeracy has been identified as an important component of health literacy. It is defined simply as "the ability to understand and use numbers in daily life", ${ }^{15}$ whereas health numeracy is defined as "the degree to which individuals have the capacity to access, process, interpret, communicate and act on numerical and probabilistic health information needed to make health decisions". ${ }^{16-18}$ Numeracy is more than mere understanding of numerical information; it can also include understanding of logic, time, and currency, and competency at performing estimations and multistep operations. ${ }^{19,20}$ Numeracy is also associated with the ability to accurately interpret the pros and cons of a given treatment and its associated risks. ${ }^{21}$

Health literacy frequently overshadows health numeracy; only recently researchers beginning to

Disclosure. Authors have no conflict of interests, and the work was not supported or funded by any drug company. This project was supported by the College of Medicine Research Centre, Deanship of Scientific Research, King Saud University, Riyadh, Saudi Arabia. recognize the importance of numeracy as a distinct concept. Although literacy and numeracy are related, many adequately literate patients can nevertheless have deficient mathematical skills. ${ }^{15,19}$ Furthermore, educational attainment can mask deficiencies in numerical abilities; ${ }^{22}$ thus, deficits in numeracy skills often remain unrecognized by healthcare providers.

Low numeracy levels were found to be associated with a higher body mass index, ${ }^{12}$ poor anticoagulation control $^{21}$ and poor health outcomes (namely, increased hospitalization) among patients with asthma. ${ }^{23}$ Also, patients with limited numeracy were found to show greater difficulty with comprehending food labels and estimating portion sizes, ${ }^{12,15}$ and to provide inaccurate dietary self-reports. ${ }^{24}$ Additionally, a recent study showed that people with diabetes who had poorer numeracy skills tended to hold inaccurate perceptions of the risks associated with diabetes. ${ }^{25}$

Diabetes numeracy has emerged as a term to reflect applied quantitative skills within the context of diabetes care. Several studies have established an association between low diabetes numeracy and poor glycemic control. ${ }^{26,27}$ Another study showed that poor diabetes numeracy among patients with type 1 and 2 diabetes was associated not only with less diabetes knowledge and perceived self-efficacy, but also with fewer selfmanagement behaviors. ${ }^{13}$

Arab adults with diabetes have suboptimal selfmanagement behaviors. ${ }^{6,7,28}$ Among several studies investigating possible factors associated with the level of diabetes self-management, ${ }^{29-31}$ numeracy has not been fully addressed. By identifying possible associations between these 2 crucial aspects, exploring diabetes numeracy in individuals with poor self-management may become a defined recommendation for practice. Ultimately, we aim to explore the level of diabetes numeracy among Saudi adults with insulin-treated diabetes and its association with diabetes selfmanagement. We hypothesize that the level of diabetes self-management correlates with the level of diabetes numeracy.

Methods. This is a cross-sectional study that describes the association between diabetes numeracy and diabetes self-management among Saudi adults with insulin-treated diabetes. From August 2018 to January 2019, we enrolled participants from 3 diabetes centers in Riyadh, Jeddah, and Buraydah, Saudi Arabia, which provide diabetes care for patients from a wide range of socioeconomic backgrounds. Potential participants were approached during their clinic visit and solicited to complete a questionnaire. Respondents were only 
attended to by the researchers while completing the questionnaire to clarify any ambiguities. Written informed consent was obtained from all participants. This study was approved by the Institutional Review Board (IRB) at King Saud University, College of Medicine, Riyadh, Saudi Arabia (approved IRB reference number 18/0302/IRB).

The included participants had type 1 or type 2 diabetes, were using insulin (with or without oral diabetes medications), and had held a diabetes diagnosis for at least one year. The participants were between 18-65 years of age and all were Arabic speakers. Exclusion criteria comprised illiteracy, a previous diagnosis of dementia or psychosis, blindness, or vision problems.

A pilot study of 20 subjects was conducted to measure the mean scores and standard deviations on the Diabetes Self-Management Questionnaire (DSMQ) in the targeted population. ${ }^{32}$ Accordingly, the sample size was calculated using a single mean formula with a $95 \%$ confidence interval.

The subjects were selected through systematic random sampling by obtaining a sampling frame of the patients attending the 3 clinics during the study period. As a starting point, a subject from each clinic appointment's list was randomly selected; then, every third patient was selected. Afterwards, the subjects who failed to meet the inclusion criteria were excluded.

Data were collected via paper-based surveys, which the participants self-administered in the presence of a researcher. The respondents' most recent hemoglobin A1c levels were obtained from their electronic charts, which were within 6 months of the patients' visit. The participants were allowed to use a calculator as needed in order to simulate real-life situations.

Study variables. The following variables were collected: age, gender, education level, social status, monthly income in Riyals, type of diabetes, type of treatment, duration of diabetes, most recent hemoglobin A1c levels, diabetes self-management level, diabetes knowledge level, and diabetes numeracy level. The study outcomes include: the level of diabetes numeracy, the level of diabetes self-management, and the association between these 2 variables.

Instruments. Diabetes self-management questionnaire (DSMQ). The level of diabetes selfmanagement was determined by the DSMQ, a validated tool developed by the Research Institute of the Diabetes Academy Mergentheim. This instrument consists of 16 items designed to assess self-care behaviors among people with diabetes on a 4-point Likert scale. The scores of each scale were calculated as sums of item scores which then were transformed into a scale ranging from 0 to 10 , with higher scores indicating higher levels of selfmanagement behaviors. ${ }^{32}$ The tool includes 4 subscales that each represents a certain domain of diabetes selfmanagement. These subscales are referred to as 'glucose management', 'dietary control', 'physical activity', and 'healthcare use', including a 'sum scale' as a global measure of self-care. We translated the tool into Arabic according to the World Health Organization (WHO) process of translation and adaptation of instruments. Permission to use this instrument was obtained from its author by e-mail.

Michigan diabetes knowledge scale (DKS). The level of diabetes knowledge was determined by the mean score of the Revised Michigan DKS-true/false version, a validated, open-access tool developed by the Michigan Diabetes Research Center (MDRC). ${ }^{33}$ The instrument was translated into Arabic as previously described.

Diabetes numeracy test (DNT-15). The level of diabetes numeracy was determined by the DNT-15, a validated tool developed by the Vanderbilt Diabetes Research and Training Center ${ }^{20}$ to assess the calculation skills needed for diabetes self-management, with higher scores indicating higher numeracy level. The Arabic version of the DNT-15 was validated in a study on a Saudi population with either type 1 or 2 diabetes in Riyadh's National Guard Hospital. ${ }^{34}$ Items responses will be scored as correct or incorrect and final scores will be converted into percentages (range: $0-100$ ). The test examines 6 main mathematical problem types, including addition and subtraction, multiplication and division, fractions and decimals, multistep mathematics, and numeration, counting, and hierarchy. In addition to the total score, individual scores were calculated for each group section. Permission to use this instrument was obtained from its author via e-mail.

Statistical analysis. Statistical analysis was performed using the Statistical Package for Social Sciences software, version 24 (Armonk, NY: IBM Corp.). ${ }^{35}$ To describe sample characteristics and responses, we used means, standard deviations, medians, interquartile ranges (IQRs) for continuous variables, and frequencies and percentages for categorical variables. The total score and subsection scores of the DNT-15 were calculated as the percentage of correctly answered questions. Unanswered questions were scored as incorrect. One-way analysis of variance (ANOVA) was used to compare the mean values of the DSMQ total score (namely, sum scale) and the DNT-15 total score in relation to participant characteristics, including diabetes knowledge level, with more than 2 categories. We used the independent t-test for the differences between binary variables and 
continuous variables. A p-value of $\leq 0.05$ and $95 \%$ confidence intervals were used to report the statistical significance and precision of the results, respectively. We used Cuzick's nonparametric test for trends across the DNT-15 score quartiles to analyze the relationship between diabetes self-management total score and diabetes numeracy score. ${ }^{36}$ The level of diabetes knowledge was determined by the DKS total score as a continuous variable, which was then categorized as representing either less than $50 \%$ or equals to or more than $50 \%$.

We also measured the duration of diabetes diagnosis as a continuous variable according to the following categories: less than 4 years, between 4 to 10 years, and more than 10 years. A simple linear regression analysis adjusted for age, gender, level of education, and diabetes knowledge was calculated to predict the DSMQ total score (dependent variable) based on the DNT-15 score (independent variable).

Results. A sample of 279 patients met the inclusion criteria and completed the questionnaire. Any questionnaires with missing information were excluded. Women comprised $58.8 \%$ of the sample (164/279), and $63 \%$ of patients were aged 30 years or younger (176/279), while $21.5 \%$ were above 45 years of age (60/279). Fifty-four percent of respondents had a monthly income less than 5,000 Saudi Riyals (SAR). Most of the patients had type 1 diabetes (72.8\%), 67\% of whom used insulin exclusively. The mean hemoglobin A1c level was found to be $9.2 \%$, and $44 \%$ of patients have been diagnosed with diabetes for more than 10 years. The majority $(81.7 \%)$ of patients scored less than $50 \%$ on the DKS (Table 1).

Diabetes self-management and patient characteristics. The subscale 'healthcare use' had the highest mean score (7.63), whereas the subscale 'diet' had the lowest mean score (5.38). The mean total scores of DSMQ were almost equal in both men and women (6.47) and almost equal among participants with type I and type II diabetes (6.45 and 6.52, respectively). On the other hand, patients whose highest formal education was primary school had a higher mean total DSMQ score than those who obtained a level of education beyond college (7.3 versus 6.8, $p=0.02$ ). Patients with a monthly income of $<5000$ SAR had a lower mean total DSMQ score compared to patients with a monthly income of $>5000 \operatorname{SAR}(p=0.02)$. Finally, the mean total DSMQ score was higher among patients who had higher diabetes knowledge levels (namely, DKS $\geq 50 \%$ ) relative to those with lower diabetes knowledge levels ( $p=0.01$; Tables $2 \& 3$ ).
DNT-15 score and patient characteristics. The mean total DNT-15 score was $41.3 \%$. The highest score was achieved in 'addition and subtraction', with a mean of 68\%, whereas 'multistep mathematics' had the lowest score $(43.1 \%)$. Sixty-three percent of the participants answered the question about 'time' correctly.

Patients who had a lower diabetes numeracy score tended to be younger, married, have a lower level of education and a lower monthly income, use insulin exclusively, and have type I diabetes. On the other hand, low diabetes knowledge was significantly associated with lower DNT-15 scores $(p<0.001)$. No significant

Table 1 - Characteristics of study sample $(n=279)$.

\begin{tabular}{|c|c|}
\hline Characteristics & n $(\%)$ \\
\hline \multicolumn{2}{|l|}{ Age (years) } \\
\hline$\leq 30$ & $176(63.1)$ \\
\hline $31-45$ & $43(15.4)$ \\
\hline$>45$ & $60(21.5)$ \\
\hline \multicolumn{2}{|l|}{ Gender } \\
\hline Male & $115(41.2)$ \\
\hline Female & $164(58.8)$ \\
\hline \multicolumn{2}{|l|}{ Level of education } \\
\hline Primary & $14(5.0)$ \\
\hline Intermediate & $16(5.7)$ \\
\hline Secondary & $108(38.7)$ \\
\hline College & $132(47.3)$ \\
\hline Higher than college & $9(3.2)$ \\
\hline \multicolumn{2}{|l|}{ Social status } \\
\hline Married & $103(36.9)$ \\
\hline Single & $160(57.3)$ \\
\hline Divorced & $9(3.2)$ \\
\hline Widowed & $7(2.5)$ \\
\hline \multicolumn{2}{|l|}{ Montbly income (SAR) } \\
\hline$<5000$ & $150(53.8)$ \\
\hline 5000 to 1000 & $58(20.8)$ \\
\hline$<10000$ to 15000 & $44(15.8)$ \\
\hline$<15000$ to 20000 & $18(6.5)$ \\
\hline$<20000$ & $9(3.2)$ \\
\hline \multicolumn{2}{|l|}{ Type of diabetes } \\
\hline Type I & $203(72.8)$ \\
\hline Type II & $76(27.2)$ \\
\hline \multicolumn{2}{|l|}{ Type of treatment } \\
\hline Insulin only & $187(67.0)$ \\
\hline Insulin with oral medications & $92(33.0)$ \\
\hline \multicolumn{2}{|l|}{ Duration of diabetes diagnosis (years) } \\
\hline$<4$ & $60(21.5)$ \\
\hline 4 to 10 & $95(34.1)$ \\
\hline$>10$ & $124(44.4)$ \\
\hline \multicolumn{2}{|l|}{$D K S$ score } \\
\hline$>50 \%$ & $51(18.3)$ \\
\hline$<50 \%$ & $228(81.7)$ \\
\hline Hemoglobin A1c level, mean $\pm S D$ & $9.28 \pm 2.35$ \\
\hline
\end{tabular}


Table 2 - DSMQ scores* $(\mathrm{n}=279)$.

\begin{tabular}{lccccc}
\hline Scales & Minimum score & Maximum score & Mean & Std. Deviation & Median, (IQR) $)^{* *}$ \\
\hline Sum-scale & 2.2 & 9.7 & 6.47 & 1.46 & $6.4(5.4-7.7)$ \\
Diet & 0.8 & 10 & 5.38 & 2.21 & $5.0(4.1-6.6)$ \\
Glucose management & 0.4 & 10 & 6.74 & 2.12 & $6.6(5.3-8.6)$ \\
Physical activity & 1.1 & 10 & 6.42 & 2.15 & $6.6(5.5-7.7)$ \\
Health-care use & 3.3 & 10 & 7.63 & 1.87 & $7.7(6.6-8.8)$ \\
\hline
\end{tabular}

*DSMQ:= Diabetes self-management questionnaire ( score range: $0-10) ;{ }^{* *} \mathrm{IQR}=$ interquartile range; sum-scale= total score

Table 3 - Characteristics of study sample by DSMQ* score $(\mathrm{n}=279)$

\begin{tabular}{|c|c|c|}
\hline Characteristics & Mean & $P$-value \\
\hline $\begin{array}{l}\text { Age (years) } \\
\quad \leq 30 \\
31-45 \\
>45\end{array}$ & $\begin{array}{l}6.33 \\
6.54 \\
6.82\end{array}$ & 0.72 \\
\hline $\begin{array}{l}\text { Gender } \\
\text { Male } \\
\text { Female }\end{array}$ & $\begin{array}{l}6.47 \\
6.47\end{array}$ & 0.975 \\
\hline $\begin{array}{l}\text { Level of education } \\
\text { Primary } \\
\text { Intermediate } \\
\text { Secondary } \\
\text { College } \\
\text { Higher than college }\end{array}$ & $\begin{array}{l}7.3 \\
6.82 \\
6.18 \\
6.55 \\
6.81\end{array}$ & 0.029 \\
\hline $\begin{array}{l}\text { Social status } \\
\text { Married } \\
\text { Single } \\
\text { Divorced } \\
\text { Widowed }\end{array}$ & $\begin{array}{l}6.67 \\
6.33 \\
7.16 \\
5.77\end{array}$ & 0.068 \\
\hline $\begin{array}{l}\text { Monthly income (SAR) } \\
\quad<5000 \\
\quad 5000 \text { to } 1000 \\
\quad<10000 \text { to } 15000 \\
\quad<15000 \text { to } 20000 \\
\quad<20000\end{array}$ & $\begin{array}{l}6.24 \\
6.63 \\
6.65 \\
7.27 \\
6.75\end{array}$ & 0.026 \\
\hline $\begin{array}{l}\text { Type of diabetes } \\
\text { Type I } \\
\text { Type II }\end{array}$ & $\begin{array}{l}6.45 \\
6.52\end{array}$ & 0.705 \\
\hline $\begin{array}{l}\text { Type of treatment } \\
\text { Insulin only } \\
\text { Insulin with oral medications }\end{array}$ & $\begin{array}{l}6.39 \\
6.63\end{array}$ & 0.2 \\
\hline $\begin{array}{l}\text { Duration of diabetes diagnosis (years) } \\
\quad<4 \\
\quad 4 \text { to } 10 \\
>10\end{array}$ & $\begin{array}{l}6.77 \\
6.38 \\
6.39\end{array}$ & 0.187 \\
\hline $\begin{array}{l}D K S \text { score } \\
\quad>50 \% \\
\quad<50 \%\end{array}$ & $\begin{array}{l}6.57 \\
6.02\end{array}$ & 0.015 \\
\hline
\end{tabular}

DSMQ: diabetes self-management questionnaire, SAR: Saudi Arabia Riyal association was found between DNT-15 scores and duration of diabetes (Table 4).

DNT-15 score and diabetes self-management. A simple linear regression analysis adjusted for age, gender, level of education, and diabetes knowledge was calculated to predict the DSMQ total score (dependent variable) based on the DNT-15 score (independent variable). Lower DNT-15 scores were modestly associated with lower DSMQ scores $(p=0.08)$. Patients who achieved the highest score in DNT-15 (82-100\%) where also found to have the highest total score in DSMQ (median: 7.0, IQR: 6.4-8.1), ( $p=0.17$; Table 5)

Discussion. The relationship between diabetes numeracy and diabetes self-management is an important, but understudied subject. Our study describes the association between diabetes numeracy and diabetes self-management behaviors. The study demonstrates that lower level of diabetes numeracy was associated with lower level of self-management behaviors. This finding is consistent with another study that has shown a similar association among patients with diabetes who are on insulin pump therapy. ${ }^{37}$ Additionally, Cavanaugh et al found that patients with higher diabetes numeracy were more likely to have a greater perceived self-efficacy for diabetes self-management. ${ }^{13}$ A possible explanation for such findings is that inadequate diabetes numeracy can also reflect a deficiency in other problem-solving skills that are required in diabetes self-management. ${ }^{12,24}$ This may highlight the importance of identifying patients with inadequate numeracy in order to further detect the deficiency in other aspects of diabetes selfmanagement.

In our patient population, the mean total DSMQ score was 6.4, which is higher compared to the mean scores of other studied population. ${ }^{38-40}$ Of note, it has been demonstrated that the association between 
Table 4 -Characteristics of study sample, by diabetes numeracy test $($ DNT-15) $(\mathrm{n}=279)$.

\begin{tabular}{|c|c|c|c|}
\hline Characteristics & $\begin{array}{c}\text { DNT-15 } \\
\text { score (Mean) }\end{array}$ & SD & $P$-value \\
\hline \multicolumn{4}{|l|}{ Age (years) } \\
\hline$\leq 30$ & 41.10 & 21.01 & \multirow{3}{*}{0.902} \\
\hline $31-45$ & 42.81 & 26.15 & \\
\hline$>45$ & 41.61 & 21.92 & \\
\hline \multicolumn{4}{|l|}{ Gender } \\
\hline Male & 43.39 & 21.59 & \multirow[t]{2}{*}{0.226} \\
\hline Female & 40.13 & 22.22 & \\
\hline \multicolumn{4}{|l|}{ Level of education } \\
\hline Primary & 34.97 & 27.42 & \multirow{5}{*}{$<0.001$} \\
\hline Intermediate & 26.07 & 15.79 & \\
\hline Secondary & 38.24 & 20.73 & \\
\hline College & 45.89 & 22.15 & \\
\hline Higher than college & 50.56 & 14.91 & \\
\hline \multicolumn{4}{|l|}{ Social status } \\
\hline Married & 42.27 & 23.59 & \multirow{4}{*}{0.959} \\
\hline Single & 41.15 & 20.74 & \\
\hline Divorced & 40.38 & 31.46 & \\
\hline Widowed & 38.57 & 16.58 & \\
\hline \multicolumn{4}{|l|}{ Monthly income (SAR) } \\
\hline$<5000$ & 37.99 & 18.79 & \multirow{5}{*}{0.033} \\
\hline 5000 to 1000 & 43.82 & 23.36 & \\
\hline$<10000$ to 15000 & 44.91 & 24.00 & \\
\hline$<15000$ to 20000 & 52.83 & 28.24 & \\
\hline$<20000$ & 44.56 & 29.86 & \\
\hline \multicolumn{4}{|l|}{ Type of diabetes } \\
\hline Type I & 41.43 & 21.73 & \multirow[t]{2}{*}{0.962} \\
\hline Type II & 41.58 & 22.83 & \\
\hline \multicolumn{4}{|l|}{ Type of treatment } \\
\hline Insulin only & & & \multirow{3}{*}{0.619} \\
\hline Insulin with oral & 41.93 & 21.42 & \\
\hline medications & 40.52 & 23.20 & \\
\hline Duration of diabetes diagnosis & 38.27 & 23.58 & \\
\hline (years) & 40.85 & 21.51 & \\
\hline$<4$ & 43.48 & 21.51 & 0.187 \\
\hline \multicolumn{4}{|l|}{4 to 10} \\
\hline \multicolumn{4}{|l|}{$>10$} \\
\hline \multicolumn{4}{|l|}{$D K S$ score } \\
\hline$>50 \%$ & 43.72 & 22.85 & \multirow[t]{2}{*}{$<0.001$} \\
\hline$<50 \%$ & 31.38 & 13.73 & \\
\hline SD: standard devia & , SAR: Saudi & abia Riy: & \\
\hline
\end{tabular}

diabetes numeracy and diabetes self-management was more pronounced among patients who used insulin. ${ }^{13}$ Furthermore, a study showed that patients with type I diabetes were found to express higher confidence in their diabetes self-management. ${ }^{41}$

Among the self-management behaviors that we examined, behaviors related to healthcare use were found to have the highest score, whereas behaviors related to dietary management scored the lowest. The exact opposite was observed in other study conducted among Iranian patients with type 2 diabetes. ${ }^{39}$ On the other hand, a study by Sayeed et $\mathrm{al}^{40}$ found that Pakistani patients with type 2 diabetes who had better glycemic control, compared to those with poor glycemic control, were found to score higher in the sub-scales related to dietary management, healthcare use and physical activity. In contrast, another study conducted among Pakistani patients with type II diabetes observed that behaviors related to glucose management scored the highest whereas physical activity behaviors scored the lowest.

A plausible explanation for these discrepancies may be that patients in our study perceived dietary management as a difficult commitment. A lack of proper diet education by healthcare providers may also play a role. According to a local study conducted in Jazan, less than half of the people with diabetes were found to adhere to their prescribed diet. ${ }^{42}$ Another local study found that $10.7 \%$ of the patients who attended a primary care center in the Eastern region held at least one misconception about a diabetes-friendly diet. ${ }^{43} \mathrm{~A}$ surprising result from our study is that patients with the lowest educational levels self-reported the highest levels of diabetes self-management. A similar finding was also observed in a local study that showed that formal education was not significantly associated with most self-care practices, and that those with formal education spent less time practicing foot care. ${ }^{28,44}$

A possible explanation of this finding is that patients with a lower level of education may be assumed by healthcare providers to hold a greater number of false perceptions about their diabetes self-management practices. This assumption by healthcare providers

Table 5 - Diabetes self-management questionnaire score (DSMQ), by diabetes numeracy test (DNT-15) score quartiles.

\begin{tabular}{lccccc}
\hline DNT-15 score quartiles & $\begin{array}{c}\text { Quartile 1 } \\
\mathbf{1 6 1 ( 0 - 4 2 \% )}\end{array}$ & $\begin{array}{c}\text { Quartile 2 } \\
\mathbf{6 4}(\mathbf{4 3 \% - 6 5 \% )}\end{array}$ & $\begin{array}{c}\text { Quartile 3 } \\
\mathbf{3 9}(\mathbf{6 6 \% - 8 1 \% )})\end{array}$ & $\begin{array}{c}\text { Quartile 4 } \\
\mathbf{1 5}(\mathbf{8 2} \%-100 \%)\end{array}$ & P-value \\
\hline $\begin{array}{l}\text { Median DSMQ score, } \\
\text { (IQR) }\end{array}$ & $\begin{array}{c}6.2 \\
(5.4-7.5)\end{array}$ & $\begin{array}{c}6.6 \\
(5.8-7.9)\end{array}$ & $\begin{array}{c}6.9 \\
(5.6-7.7)\end{array}$ & $\begin{array}{c}7.0 \\
(6.4-8.1)\end{array}$ & 0.173 \\
\hline
\end{tabular}


may lead them to provide additional information and self-management instructions to patients with less educational achievement than to more highly educated patients. This finding highlights the importance of educating all patients about proper self-management regardless of their level of education.

Another possible explanation is that patients with lower levels of education are more likely to compensate by soliciting support from their family or caregivers, which may affect self-assessment of their diabetes management. Similarly, Fransen et $\mathrm{al}^{45}$ found that social support mediated the relationship between health literacy and diabetes self-management. One may also hypothesize that lower levels of education may lead to an over-estimated perception of self-management behaviors. Findings from a local study indicated that participants' perception of their control over their health condition, in addition to their religious beliefs, influenced their adherence to self-care activities. ${ }^{46}$ Furthermore, patients of our study had a lower mean diabetes numeracy score $(41.3 \%)$ in comparison to other studied patients. ${ }^{13,34,37}$ Saudi patients of another study had a relatively higher mean diabetes numeracy score $(53.3 \%) .{ }^{34}$ Also, another study demonstrated that $60 \%$ of patients on insulin pump therapy scored $90 \%$ and higher on DNT-15 test. ${ }^{37}$ Additionally, the patients in our study were found to perform best at addition and subtraction, and worst at multistep mathematics. This finding highlights the fact that patients with low diabetes numeracy could not perform most of the basic mathematical tasks required for diabetes management, such as identifying abnormal glucose values and calculating insulin doses. Similarly, patients on insulin pump therapy were found to score the lowest in tasks related to calculating carbohydrates content from nutrition labels, adjusting diet based on exercise and adjusting insulin doses based on carbohydrates intake and glucose levels. ${ }^{37}$

In our study, patients who had lower diabetes numeracy tended to be younger, have lower levels of education, have a lower monthly income, have type I diabetes, and have greater diabetes knowledge. Cavanaugh et $\mathrm{al}^{13}$ found strikingly similar results; however, they also found that patients with a lower diabetes numeracy were more likely to be older and have type II diabetes. Similarly, Turrin et $\mathrm{al}^{37}$ also found that patients on insulin pump therapy who had lower diabetes numeracy tended to be older. One may hypothesize that older patients are often diagnosed with diabetes long enough before the younger patients, which in turns can aid them in acquiring some numerical skills in the context of diabetes self-management. Furthermore, our study demonstrates that a higher level of diabetes knowledge was significantly associated with a higher level of diabetes numeracy, a finding that was similarly observed by Cavanaugh et al. ${ }^{13}$ This may be explained by the possible influence of diabetes knowledge on the patient's ability to interpret and act upon some of the findings that require numerical skills.

It is interesting to note that, as observed in previous studies, ${ }^{13,34,47}$ lower diabetes numeracy was not significantly associated with duration of diabetes. A likely explanation is that patients with a longer duration of diabetes have had a longer period of time within which to acquire certain skills to compensate for numeracy skills deficits.

Study limitations. Our study examines the relationship between diabetes numeracy and diabetesself management in the region to examine the relationship between diabetes numeracy and diabetesself management. Furthermore, our study included a broad population of both type I and type II diabetes patients from 3 diverse centers that provide diabetes care for patients from a wide range of socioeconomic backgrounds. This can ensure a better generalizability of our study findings on a larger scale. On the other hand, this study has some limitations that are worth mentioning. First, the study used a cross-sectional design, which describes associations; however, it does not make a conclusion regarding causation. Second, the participants completed the questionnaire in the presence of the researchers; although researchers were careful to only provide clarifications and instructions, the influence of their guidance on the participants' performance cannot be entirely excluded. Finally, although DNT-15 test is designed to assess patients' current diabetes numeracy, the performance on this test may also be affected by the patients' level of diabetes knowledge or previous diabetes education.

In conclusion, diabetes numeracy is a newly emerging issue that requires further investigation. More specifically, the mechanism by which diabetes numeracy affects self-management practices, that are not necessarily mathematical, remains poorly understood. We have observed that lower diabetes numeracy was associated with poorer diabetes self-management, a point worth considering in designing and implementing diabetes self-management education. However, there was nonsignificant association between diabetes numeracy and the level of diabetes self-management $(p=0.08)$.

We have also observed that a large portion of patients with insulin-treated diabetes could not perform the basic mathematical skills that are essential for selfmanagement, especially with insulin therapy. We believe 
that providers should be considerate of and know how to assess patients' diabetes numeracy in order to deliver a care that acknowledges patients' numeracy level, and eventually, to improve patients' self-management. Finally, developing a self-management assessment tool that directly measures the numeracy-dependent practices of self-management is a promising area for future research.

Acknowledgment. We would like to thank Layla M. Albreacan for her effective contribution in data collection.

\section{References}

1. Saeedi P, Petersohn I, Salpea P, Malanda B, Karuranga S, Unwin $\mathrm{N}$, et al. IDF Diabetes Atlas Committee. Global and regional diabetes prevalence estimates for 2019 and projections for 2030 and 2045: Results from the International Diabetes Federation Diabetes Atlas, 9th edition. Diabetes Res Clin Pract 2019; 157: 107843.

2. Alzaheb RA, Altemani AH. The prevalence and determinants of poor glycemic control among adults with type 2 diabetes mellitus in Saudi Arabia. Diabetes Metab Syndr Obes 2018; 11 : 15-21.

3. Alsulaiman TA, Al-Ajmi HA, Al-Qahtani SM, Fadlallah IM, Nawar NE, Shukerallah RE, et al. Control of type 2 diabetes in King Abdulaziz Housing City (Iskan) population, Saudi Arabia. J Family Community Med 2016; 23: 1-5.

4. Azab AS. Glycemic control among diabetic patients. Saudi Med J 2001; 22: 407-409.

5. Montague MC, Nichols SA, Dutta AP. Self-management in African American women with diabetes. Diabetes Educ 2005; 31: 700-711.

6. ALAboudi IS, Hassali MA, Shafie AA, Saleem F. Self-efficacy, self-care behaviours and glycaemic control in type 2 diabetic patients in Riyadh, Saudi Arabia. Journal of Public Health. 2016; 24: 281-290.

7. Al-Khawaldeh OA, Al-Hassan MA, Froelicher ES. Self-efficacy, self-management, and glycemic control in adults with type 2 diabetes mellitus. J Diabetes Complications 2012; 26: 10-16.

8. Chan JC, Gagliardino JJ, Baik SH, Chantelot JM, Ferreira SR, Hancu N, et al. Multifaceted determinants for achieving glycemic control: the International Diabetes Management Practice Study (IDMPS). Diabetes Care 2009; 32: 227-233.

9. Povey RC, Clark-Carter D. Diabetes and healthy eating: a systematic review of the literature. Diabetes Educ 2007; 33: 931-959.

10. Deakin T, McShane CE, Cade JE, Williams RD. Group based training for self-management strategies in people with type 2 diabetes mellitus. Cochrane Database Syst Rev 2005; (2): CD003417.

11. Wolff K, Cavanaugh K, Malone R, Hawk V, Gregory BP, Davis D, et al. The Diabetes Literacy and Numeracy Education Toolkit (DLNET): materials to facilitate diabetes education and management in patients with low literacy and numeracy skills. Diabetes Educ 2009; 35: 233-226.

12. Huizinga MM, Beech BM, Cavanaugh KL, Elasy TA, Rothman RL. Low numeracy skills are associated with higher BMI. Obesity (Silver Spring) 2008; 16: 1966-1968.
13. Cavanaugh K, Huizinga MM, Wallston KA, Gebretsadik T, Shintani A, Davis D, et al. Association of numeracy and diabetes control. Ann Intern Med 2008; 148: 737-46.

14. Osborn CY, Cavanaugh K, Wallston KA, Rothman RL. Selfefficacy links health literacy and numeracy to glycemic control. J Health Commun 2010; 15 (Suppl 2): 146-158.

15. Rothman RL, Housam R, Weiss H, Davis D, Gregory R, Gebretsadik T,et al. Patient understanding of food labels: the role of literacy and numeracy. Am J Prev Med 2006; 31 : 391-398.

16. Ancker JS, Kaufman D. Rethinking health numeracy: a multidisciplinary literature review. J Am Med Inform Assoc. 2007; 14: 713-721.

17. Golbeck AL, Ahlers-Schmidt CR, Paschal AM, Dismuke SE. A definition and operational framework for health numeracy. Am J Prev Med. 2005; 29: 375-376.

18. Donelle L, Hoffman-Goetz L, Gatobu S, Arocha JF. Comprehension of Internet-based numeric cancer information by older adults. Inform Health Soc Care 2009; 34: 209-224.

19. Montori VM, Rothman RL. Weakness in numbers. The challenge of numeracy in health care. J Gen Intern Med 2005; 20: 1071-1072.

20. Huizinga MM, Elasy TA, Wallston KA, Cavanaugh K, Davis D, Gregory RP, et al. Development and validation of the Diabetes Numeracy Test (DNT). BMC Health Serv Res 2008; 8: 96.

21. Estrada CA, Martin-Hryniewicz M, Peek BT, Collins C, Byrd JC. Literacy and numeracy skills and anticoagulation control. Am J Med Sci 2004; 328: 88-93.

22. Lipkus IM, Samsa G, Rimer BK. General performance on a numeracy scale among highly educated samples. Med Decis Making 2001; 21: 37-44.

23. Rosas-Salazar C, Ramratnam SK, Brehm JM, Han YY, AcostaPérez E, Alvarez $M$, et al. Parental numeracy and asthma exacerbations in Puerto Rican children. Chest 2013; 144: 92-98.

24. Bowen ME, Cavanaugh KL, Wolff K, Davis D, Gregory B, Rothman RL. Numeracy and dietary intake in patients with type 2 diabetes. Diabetes Educ 2013; 39: 240-247.

25. Simonds VW, Omidpanah A, Buchwald D. Diabetes prevention among American Indians: the role of self-efficacy, risk perception, numeracy and cultural identity. BMC Public Health 2017; 17: 763.

26. Cavanaugh K, Wallston KA, Gebretsadik T, Shintani A, Huizinga MM, Davis D, et al. Addressing literacy and numeracy to improve diabetes care: two randomized controlled trials. Diabetes Care 2009; 32: 2149-2155.

27. Marden S, Thomas PW, Sheppard ZA, Knott J, Lueddeke J, Kerr D. Poor numeracy skills are associated with glycaemic control in type 1 diabetes. Diabet Med 2012; 29: 662-669.

28. Al Johani KA, Kendall GE, Snider PD. Self-management practices among type 2 diabetes patients attending primary health-care centres in Medina, Saudi Arabia. EMHJ-Eastern Mediterranean Health Journal 2015; 21: 621-628.

29. Luo X, Liu T, Yuan X, Ge S, Yang J, Li C, et al. Factors influencing self-management in Chinese adults with type 2 diabetes: A systematic review and meta-analysis. Int J Environ Res Public Health 2015; 12: 11304-11327.

30. Devarajooh C, Chinna K. Depression, distress and self-efficacy: The impact on diabetes self-care practices. PLoS One 2017; 12: e0175096. 
31. Gharaibeh B, Gajewski BJ, Al-smadi A, Boyle DK. The relationships among depression, self-care agency, self-efficacy and diabetes selfcare management. Journal of Research in Nursing 2016; 21: 110-122.

32. Schmitt A, Gahr A, Hermanns N, Kulzer B, Huber J, Haak T. The Diabetes Self-Management Questionnaire (DSMQ): development and evaluation of an instrument to assess diabetes self-care activities associated with glycaemic control. Health Qual Life Outcomes 2013; 11: 138.

33. Collins GS, Mughal S, Barnett AH, Fitzgerald J, Lloyd CE. Modification and validation of the revised diabetes knowledge scale. Diabet Med 2011; 28: 306-310.

34. Alghodaier H, Jradi H, Mohammad NS, Bawazir A. Validation of a diabetes numeracy test in Arabic. PloS One 2017; 4: e0175442.

35. IBM Corp. Released 2016. IBM SPSS Statistics for Windows, Version 24.0. Armonk (NY): IBM Corp. Available from: https://www.ibm.com/sa-en

36. Cuzick J. A Wilcoxon-type test for trend. Statistics in Medicine 1985; 4: 543-547.

37. Turrin KB, Trujillo JM. Effects of diabetes numeracy on glycemic control and diabetes self-management behaviors in patients on insulin pump therapy. Diabetes Ther 2019; 10: 1337-1346.

38. Sayeed KA, Qayyum A, Jamshed F, Gill U, Usama SM, Asghar $\mathrm{K}$, Tahir A. Impact of diabetes-related self-management on glycemic control in type II diabetes mellitus. Cureus 2020; 12 : e7845.

39. Mehravar F, Mansournia MA, Holakouie-Naieni K, NasliEsfahani E, Mansournia N, Almasi-Hashiani A. Associations between diabetes self-management and microvascular complications in patients with type 2 diabetes. Epidemiol Health 2016; 38: e2016004.
40. Bukhsh A, Khan TM, Sarfraz Nawaz M, Sajjad Ahmed H, Chan KG, Goh BH. Association of diabetes knowledge with glycemic control and self-care practices among Pakistani people with type 2 diabetes mellitus. Diabetes Metab Syndr Obes 2019; 12: 1409-1417.

41. Abubakari, A. R., Cousins, R., Thomas, C., Sharma, D., \& Naderali, E. K. Sociodemographic and clinical predictors of self-management among people with poorly controlled type 1 and type 2 diabetes: the role of illness perceptions and selfefficacy. J Diabetes Res 2016; 2016: 6708164.

42. Bani IA. Prevalence, knowledge, attitude and practices of diabetes mellitus among Jazan population, Kingdom of Saudi Arabia (KSA). Journal of Diabetes Mellitus 2015; 5: 115.

43. Sabra AA, Taha AZ, Al-Zubier AG, Al-Kurashi NY. Misconceptions about diabetes mellitus among adult male attendees of primary health care centers in Eastern Saudi Arabia. South African Family Practice 2010; 52: 344-349.

44. Al-Rasheedi AA. The role of educational level in glycemic control among patients with type II diabetes mellitus. Int J Health Sci (Qassim) 2014; 8: 177-187.

45. Fransen MP, von Wagner C, Essink-Bot ML. Diabetes selfmanagement in patients with low health literacy: ordering findings from literature in a health literacy framework. Patient Educ Couns 2012; 88: 44-53.

46. Albargawi M, Snethen J, Gannass AA, Kelber S. Perception of persons with type 2 diabetes mellitus in Saudi Arabia. International Journal of Nursing Sciences 2016; 3: 39-44.

47. Zaugg SD, Dogbey G, Collins K, Reynolds S, Batista C, Brannan G, et al. Diabetes numeracy and blood glucose control: association with type of diabetes and source of care. Clin Diabetes 2014; 32: 152-157. 